\title{
Brain microvascular pericytes are immunoactive in culture: cytokine, chemokine, nitric oxide, and LRP-1 expression in response to lipopolysaccharide
}

\author{
Andrej Kovac ${ }^{2,4}$, Michelle A Erickson ${ }^{1,3}$ and William A Banks ${ }^{1,2,3^{*}}$
}

\begin{abstract}
Background: Brain microvascular pericytes are important constituents of the neurovascular unit. These cells are physically the closest cells to the microvascular endothelial cells in brain capillaries. They significantly contribute to the induction and maintenance of the barrier functions of the blood-brain barrier. However, very little is known about their immune activities or their roles in neuroinflammation. Here, we focused on the immunological profile of brain pericytes in culture in the quiescent and immune-challenged state by studying their production of immune mediators such as nitric oxide (NO), cytokines, and chemokines. We also examined the effects of immune challenge on pericyte expression of low density lipoprotein receptor-related protein-1 (LRP-1), a protein involved in the processing of amyloid precursor protein and the brain-to-blood efflux of amyloid- $\beta$ peptide.

Methods: Supernatants were collected from primary cultures of mouse brain pericytes. Release of nitric oxide (NO) was measured by the Griess reaction and the level of S-nitrosylation of pericyte proteins measured with a modified "biotin-switch" method. Specific mitogen-activated protein kinase (MAPK) pathway inhibitors were used to determine involvement of these pathways on NO production. Cytokines and chemokines were analyzed by multianalyte technology. The expression of both subunits of LRP-1 was analyzed by western blot.

Results: Lipopolysaccharide (LPS) induced release of NO by pericytes in a dose-dependent manner that was mediated through MAPK pathways. Nitrative stress resulted in S-nitrosylation of cellular proteins. Eighteen of twenty-three cytokines measured were released constitutively by pericytes or with stimulation by LPS, including interleukin (IL)-12, IL-13, IL-9, IL-10, granulocyte-colony stimulating factor, granulocyte macrophage-colony stimulating factor, eotaxin, chemokine (C-C motif) ligand (CCL)-3, and CCL-4. Pericyte expressions of both subunits of LRP-1 were upregulated by LPS.

Conclusions: Our results show that cultured mouse brain microvascular pericytes secrete cytokines, chemokines, and nitric oxide and respond to the innate immune system stimulator LPS. These immune properties of pericytes are likely important in their communication within the neurovascular unit and provide a mechanism by which they participate in neuroinflammatory processes in brain infections and neurodegenerative diseases.
\end{abstract}

Keywords: mouse brain pericytes, LPS, neurovascular unit, cytokines, chemokines, LRP-1, Alzheimers disease, nitric oxide

\footnotetext{
* Correspondence: wabanks1@uw.edu

${ }^{1}$ Geriatrics Research Education and Clinical Center, Veterans Affairs Puget

Sound Health Care System, Seattle, Washington, USA

Full list of author information is available at the end of the article
} 


\section{Background}

The blood-brain barrier (BBB) is a selective barrier that is created by the endothelial cells in cerebral microvessels. Endothelial cells and supporting cells such as astrocytes, pericytes, neurons, and perivascular microglia are organized together to form the "neurovascular unit" which is essential for induction, function, and support of the BBB [1]. In contrast to the considerable knowledge characterizing the crosstalk among brain endothelial cells, astrocytes, and microglia within the neurovascular unit during inflammation, very little is known about the role played by the brain microvascular pericyte.

Among the cells of the neurovascular unit, brain microvascular pericytes are physically the cells closest to brain endothelial cells, wrapping around them, joined to them by gap junctions, and interfacing with them by peg-and-socket structures $[2,3]$. These cells are also essential for the induction of the barrier properties of the $\mathrm{BBB}$ and attrition of pericytes during the neovascularization process [4] or aging [5] can lead to increased vascular permeability. Furthermore, it has been described that pericytes regulates BBB-specific gene expression in endothelial cells and induces polarization of astrocyte end-feets [6].

The exact contribution of pericytes to regulation of brain blood capillary flow is still not adequately examined. Early ultrastructural studies showed that cerebellar pericytes contains microfilaments similar to actin- and myosin-containing muscle fibers $[7,8]$. Furthermore, it has been described that at least some subpopulations of brain pericytes express contractile proteins such as $\alpha$-smooth muscle actin and non-muscle myosin $[9,10]$. More recently, using the acute brain tissue preparation, Peppiatt et al., showed dilatation of cerebellar pericytes as an response to glutamate stimulation [11]. Studies on cultured pericytes support contractile role of these cells however the expression of contractile proteins such as $\alpha$-smooth muscle actin seems to be changed after cultivation [12].

Several in-vitro studies exist that demonstrated that pericytes are multipotent cells. Pericytes isolated from adult brains can differentiate into cells of neural lineage [13]. Cultured brain pericytes express macrophage markers ED-2 and CD11b and to exhibit phagocytic activity, thus expressing immune cell properties [14].

During pathological conditions such as sepsis, pericytes detach from the basal lamina which leads to increased cerebrovascular permeability. Activation of pericytes through TLR-4 has been suggested to be responsible for this process [15].

Here, we focused on the immunological profile of cultured mouse brain pericytes in the quiescent and immune-challenged state. We studied production of immune mediators such as nitric oxide (NO), cytokines, and chemokines. We also examined the effects of immune activation on pericyte expression of low density lipoprotein receptor-related protein-1 (LRP-1), an immunemodulated processor of amyloid precursor protein and a brain-to-blood efflux pump for amyloid beta peptide.

\section{Methods}

\section{Mouse brain pericytes culture}

Primary mouse brain microvascular pericytes were prepared according to Nakagawa et al [16]. Briefly, cultures of mouse cerebrovascular pericytes were obtained by a prolonged, 2-week culture of isolated brain microvessel fragments, containing pericytes and endothelial cells. Pericyte survival and proliferation was favored by selective culture conditions using uncoated dishes and DMEM F12 supplemented with $20 \%$ fetal calf serum (Sigma, USA), L-glutamine (2 mM, GIBCO, USA) and gentamicin (Sigma, USA). Culture medium was changed twice a week.

\section{Cell stimulation}

Mouse brain microvascular pericyte cultures (p2-p8) were stimulated with lipopolysaccharide from Salmonella typhimurium (L6511; Sigma, USA) for 4, 8, and 24 hours. For MAPK pathways study, SB203580 (p38 MAPK inhibitor, Tocris, USA), PD98059 (MAPKK/MEK inhibitor, Tocris, USA), UO126 (MEK-1/MEK-2 inhibitor, Tocris, USA), SP600126 (c-Jun N-Terminal kinase inhibitor, Sigma, USA) and PTDC (NF- $\kappa$ B inhibitor, Sigma, USA) were added to the pericytes cultivated in 96 well plates $1 \mathrm{~h}$ before cell stimulation with LPS.

\section{Nitrite assay and detection of S-nitrosylated proteins}

Nitrite, a downstream product of nitric oxide (NO), was measured by the Griess reaction in culture supernatants as an indicator of NO production. Briefly, $50 \mathrm{ul}$ of cell culture medium was incubated with 100 ul of Griess reagent A ( $1 \%$ sulfanilamide, $5 \%$ phosphoric acid; Sigma, USA) for $5 \mathrm{~min}$, followed by addition of $100 \mathrm{ul}$ of Griess reagent B (0.1\% N-(1-naphtyl) ethylenediamine; Sigma, USA) for $5 \mathrm{~min}$. The absorbance was determined at 540 $\mathrm{nm}$ using a microplate reader.

Assessment of S-nitrosylation was done by a modification of the "biotin-switch" method. Cells were washed in PBS and lysed in lysis buffer contain NEM ( $N$-ethylmaleimide) to block free thiol groups. $S$-nitrosothiols were then reduced, biotinylated and visualized after SDS-PAGE/western blot using a streptavidin-based detection system (Cayman Chemical Company, USA). Membranes were digitalized with a LAS4000 CCD imaging system (GE Healthcare, USA) and analyzed by ImageQuant TL software.

\section{Measurement of cytokines and chemokines}

Concentrations of cytokines and chemokines secreted into the culture media were measured by a commercial 
magnetic bead based Multiplex ELISA kit (Bioplex, Biorad, USA) according to the manufacturer's protocol.

\section{Immunocytochemistry}

Pericytes grown on glass cover slips (12 mm diameter) were washed in PBS and fixed with 4\% PFA for $10 \mathrm{~min}$ at $4{ }^{\circ} \mathrm{C}$. Cells were permeabilized with $0.2 \%$ TRITONX100, blocked with 5\% BSA, and then incubated with anti- $\alpha$ smooth muscle actin antibody (Abcam, USA), anti-CD13 antibody (Abcam, USA), Griffonia simplicifolia lectin-FITC (Sigma, USA), anti-factor VIII antibody (Sigma, USA) and anti-GFAP antibody (Abcam, USA) followed by incubation with corresponding ALEXA Fluor-488 or Alexa Fluor-546 conjugated secondary antibody (Invitrogen-Molecular Probes, USA). Finally, slides were mounted in fluorescence mounting media and photographed with a Nikon ECLIPSE E800 fluorescence microscope.

\section{Western blotting}

For LRP-1, pericyte extracts were run on a 3-8\% Trisacetate gel (non-reducing conditions), transferred onto nitrocellulose membranes (Invitrogen, USA), and probed first with a LRP-1 primary antibody that recognizes the large subunit (Sigma, USA) and then with a LRP-1 primary antibody that recognizes the small subunit (Epitomics, 2703-1). SYPRO Ruby (Invitrogen, USA) staining of membranes was used to verify uniformity of protein loading [17]. Incubation with primary antibodies was followed by horseradish peroxidase-conjugated secondary antibody (Santa Cruz, USA). As positive and negative controls, respectively, MEF-1 (SV40 transformed mouse embryo fibroblasts, ATCC, USA) and PEA-13 (mouse embryo fibroblasts, ATCC, USA) cell lysates were loaded onto the gel. The enhanced chemiluminescence western blot was digitalized with a LAS4000 CCD imaging system (GE Healthcare, USA) and analyzed by ImageQuant TL software.

\section{Data analysis}

Values are presented as means \pm SEM. More than two means were compared by one-way ANOVA followed by Tukey's multiple comparison test (Prism 5.0 software, GraphPad, inc, San Diego, CA). Differences at $\mathrm{P}<0.05$ were accepted as statistically significant.

\section{Results}

\section{Characterization of purity of primary mouse brain} pericyte cultures

Purity of isolated primary mouse brain pericytes was analyzed by immunocytochemical staining of cultures. We evaluated the presence of contaminating astrocytes, microglia and endothelial cells. More than 95\% of cells in cultures was positive for the pericyte markers $\alpha$ - smooth muscle actin [14,18] (Figure 1A) and CD13 (aminopeptidase N) [19-22] (Figure 1B). Results demonstrated that there was no contamination of our primary pericyte cultures either with astrocytes (Figure 1C), microglia (Figure 1D) or endothelial cells (Figure 1E).

\section{LPS induces nitric oxide production via MAPK pathways in mouse brain pericytes}

Activation of immune cells is accompanied by production of different immune mediators. Thus, we studied the effect of LPS on production of nitric oxide (NO) and various cytokines and chemokines by cultured primary brain pericytes. Pericytes were treated for 4, 8 and $24 \mathrm{~h}$ with different concentrations of the LPS and nitrite (a downstream product of NO) concentration in cell culture media was measured. LPS at concentrations of 0.1 and $1 \mu \mathrm{g} / \mathrm{ml}$ after 8 and $24 \mathrm{~h}$ significantly induced NO release (for example, 24 h results: controls: $0.5 \pm$ $0.15 \mathrm{uM}$ at $24 \mathrm{~h} ; 0.1 \mathrm{ug} / \mathrm{ml}$ LPS: $4.3 \pm 0.77 \mathrm{uM} ; 1 \mathrm{ug} / \mathrm{ml}$ LPS: $6.4 \pm 0.98 \mathrm{uM} ; \mathrm{n}=8$ /group). There was no change in NO production at $4 \mathrm{~h}$. (Figure 2A) Production of reactive nitrogen species led to increased S-nitrosylation of pericyte proteins $(2.4 \times$ in $0.1 \mathrm{ug} / \mathrm{ml}$ LPS vs CTRL, $n$ = 3) (Figure 2B).

To identify the signal transduction pathway responsible for production of reactive nitrogen species, we tested several MAPK inhibitors and the NF- $\kappa$ B inhibitor PDTC for their ability to reduce NO production by pericytes. Preincubation of cells with SB203580 (at $20 \mathrm{uM}$; p38 MAPK inhibitor), PD98059 (at 5 and 50 uM; MAPKK/MEK inhibitor), UO126 (at 5 and $20 \mathrm{uM}$; MEK-1/MEK-2 inhibitor), SP600126 (at $50 \mathrm{uM}$; c-Jun N-Terminal kinase inhibitor) and PTDC (at $5 \mathrm{uM}$ ) significantly inhibited production of NO by cultured brain pericytes (Figure 3 ). These results indicated involvement of the MAPK signaling pathway in LPS-induced NO production.

\section{LPS stimulates cytokine and chemokine release by primary mouse brain pericytes}

Pericytes spontaneously released several interleukins (IL), including IL-9, IL-10, IL-12(p70), IL-13, and IL-17. Levels of IL-1 alpha, IL-3, and IL-12(p40) were not detectable. Other cytokines and chemokines that were detected were tumor necrosis factor-alpha, interferongamma, granulocyte-colony stimulating factor, granulocyte macrophage-colony stimulating factor, eotaxin, CCL-3 and CCL-4. To further characterize pericyte immune capacity, we determined the effect of LPS on the release of cytokines and chemokines. The results (Figure 4) showed that stimulation of primary mouse brain pericyte cultures with 0.1 and $1 \mathrm{ug} / \mathrm{ml}$ LPS resulted in significant release of pro-inflammatory cytokines such as IL-1 $\alpha$, TNF- $\alpha$, IL-3, IL-9 and IL-13 (4 h, 8 $\mathrm{h}$ and $24 \mathrm{~h}$ ) and anti-inflammatory cytokines such as IL- 

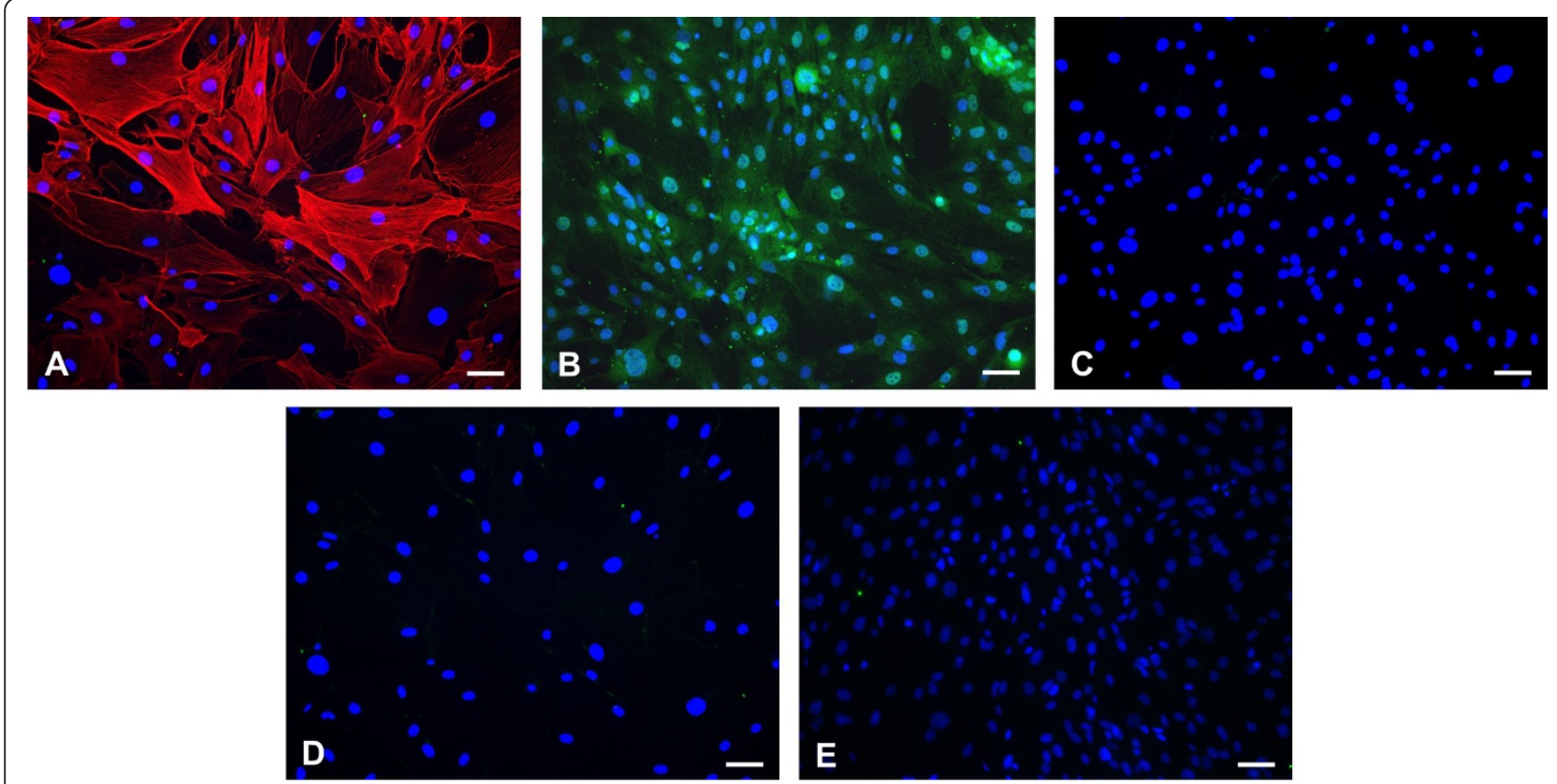

Figure 1 Determination of the purity of the pericyte culture. A primary culture of pericytes isolated from mouse brain microvessels was labeled with anti- $\alpha$ smooth muscle actin antibody (pericyte marker; red) (Panel A), anti-CD13 antibody (pericyte marker; green) (Panel B), antiGFAP antibody (astrocytes marker; green) (Panel C), Griffonia simplicifolia lectin (microglial marker; green) (Panel D) or anti-factor VIII antibody (endothelial cell marker; green) (Panel E) and counterstained with nuclear stain DAPI (blue). Visual observation of immunostained cells in pericyte cultures demonstrates that they primarily consist of a $\alpha$-smooth muscle actin/CD13 positive pericytes. No contamination with microglia, astrocytes or endothelial cells was detected. Scale bar: $40 \mu \mathrm{m}$.

10 (4 h, 8 h, 24 h). Additionally, LPS-stimulated pericytes significantly increased their secretion of IL12 heterodimer (p70) and of its p40 subunit. Moreover, activated pericytes produced more chemokines such as G-CSF, eotaxin, CCL-3, CCL-4 (4 h, $8 \mathrm{~h}$ and $24 \mathrm{~h})$ and MCP-1, KC, CCL-5 (4 h, 8 h, 24 h; data not shown) in comparison to unstimulated control cells. Of the detected cytokines, only the increase in IL-17 was not significant. There was no detectable constitutive or LPSinduced production of IL-1b, IL-2, IL- 4 and IL- 5 by brain pericytes.

\section{LPS induces up-regulation of LRP-1 expression in brain pericytes}

Neuroinflammation plays an important role in neurodegeneration. Here, we analyzed the effect of LPS on

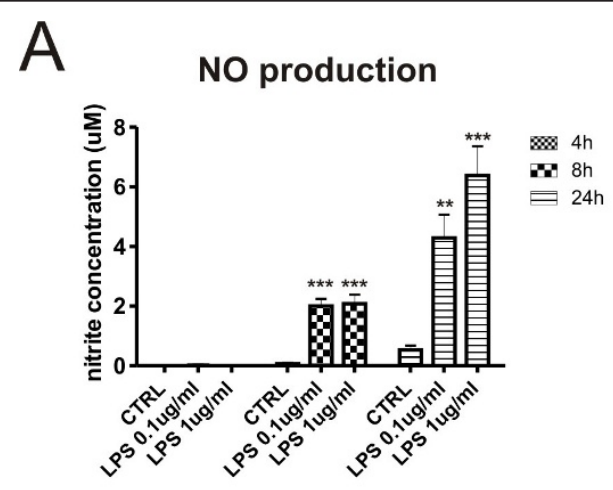

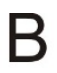

B

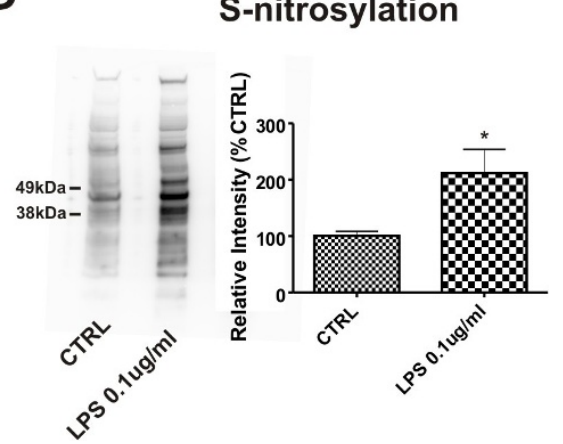

Figure 2 Release of nitric oxide and nitrosative stress in primary brain pericytes after LPS stimulation. Brain pericytes were stimulated for 4, 8, and $24 \mathrm{~h}$ with LPS $(0.1$ and $1 \mathrm{ug} / \mathrm{ml})$, media collected, and analyzed for NO production by the Griess reaction. LPS $(0.1 \mathrm{ug} / \mathrm{ml} \mathrm{and} 1 \mu \mathrm{gg} / \mathrm{ml})$ induced a significant NO release from cells after 8 and 24 hours (A). Nitrative stress was accompanied by massive S-nitrosylation of cellular proteins (B). Values of nitrite accumulation from treated cells represent the mean \pm SEM of two independent experiments conducted in tetraplicates. ${ }^{*} \mathrm{P}<0.05,{ }^{* *} \mathrm{P}<0.01,{ }^{* * *} \mathrm{P}<0.001$ vs. untreated cells. 


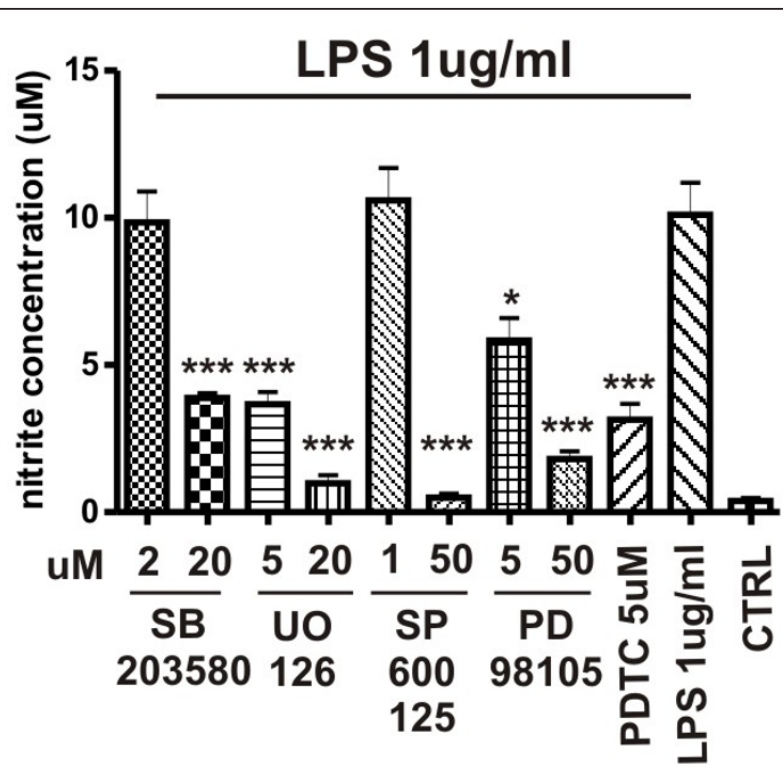

Figure 3 Involvement of MAPK pathways in nitric oxide production by pericytes after LPS stimulation. Brain pericytes were stimulated for 4,8 , and $24 \mathrm{~h}$ with LPS $(0.1$ and $1 \mathrm{ug} / \mathrm{ml})$. MAPK pathway inhibitors were added to the culture medium $1 \mathrm{~h}$ before LPS treatment. Media was collected and analyzed for NO production by Griess reaction. Addition of MAPK pathways inhibitors significantly reduced NO production by LPS treated pericytes. Values represent the mean \pm SEM of two independent experiments conducted in tetraplicates. ${ }^{*} P<0.05,{ }^{* * *} P<0.001$ vs. untreated cells.

expression of LRP-1 in pericytes. Stimulation of cells with LPS $(1 \mathrm{ug} / \mathrm{ml})$ for 24 hours significantly increased expression of both subunits of LRP-1 protein (Figure $5 \mathrm{~A}$ representative $\mathrm{WB}$ and quantification Figure $5 \mathrm{~B})$. The MEF1 (LRP-1 wild type) and PEA13 (LRP-1 knockout) cells were used as positive and negative controls respectively for LRP-1 antibodies.

\section{Discussion}

In this work, we focused on the characterization of the immunological properties of mouse brain pericytes under inflammatory conditions induced by LPS. We have used primary mouse brain pericytes as a model cell culture for our studies. These cells were isolated by modifications of the method for isolation of microcapillaries from mouse brains. However, such isolation procedures potentially can lead to cultures that are contaminated with adjacent cell types such as astrocytes, endothelial cells, and juxtavascular microglia; furthermore, the presence of these contaminating cells can lead to erroneous results $[23,24]$. Staining with markers for microglia, astrocytes and endothelial cells that are not expressed by pericytes [18], showed that our cultures were free of these cell types.

Nitric oxide (NO) is a signaling molecule and immune mediator that is released from glial and endothelial cells with activation. Microglia and astrocytes are common sources of $\mathrm{NO}$ in the brain during $\mathrm{CNS}$ inflammatory processes [25]. Production of large amounts of NO by iNOS-2 can lead to generalized nitrosative stress in cells and to posttranslational modification of protein residues by S-nitrosylation. S-nitrosylation mediates many of the biological effects of NO. This posttranslational modification causes specific physiological or pathophysiological activities by modifying protein thiols [26]. S-nitrosylated of peptides or proteins are involved in many human diseases such as type II diabetes, Alzheimer's disease, and Parkinson's disease [27]. Our results demonstrated that LPS strongly induces production of nitric oxide and nitrosative stress in brain pericytes. Furthermore, we found increased S-nitrosylation of pericyte proteins. It will be important to further analyze and study those pericyte proteins which are affected by increased Snitrosylation of their thiol residues.

Mitogen-activated protein kinase (MAPK) signal transduction pathways belong to the most prevalent mechanisms of eukaryotic cells that respond to extracellular stimuli [28]. We used several MAPK pathway inhibitors to analyze the involvement of these pathways in the release of nitric oxide by brain pericytes in response to LPS. Our results clearly showed that production of NO was blocked by pre-incubation of pericytes with these drugs. These results agree with those obtained from lung microvascular pericytes [29] and indicate that similar mechanisms are involved in activation of brain microvascular pericytes by LPS.

Another interesting finding of our study is related to the production of important signaling molecules, cytokines and chemokines by pericytes. Of 23 cytokines and chemokines that we studied, 18 were secreted by brain pericytes constitutively or in response to LPS stimulation. LPS is derived from the bacterial coat of gram negative bacteria and is a strong stimulant of the innate immune system. Among the several cytokines and chemokines whose production was increased by LPS, IL-12, IL-13, and IL-9 are of particular interest with regard to pericyte communication within the neurovascular unit. IL-12 plays a critical role in the early inflammatory response to infection. An increased production of IL-12 is involved in the pathogenesis of a number of autoimmune inflammatory diseases (multiple sclerosis, arthritis, insulin dependent diabetes) [30-32]. IL-12 consists of two subunits (p40 and p35) which are linked together by a disulfide bond to give heterodimeric p70 molecule [33]. We showed that brain pericytes release substantial amounts of both the heterodimeric p70 molecule and p40 subunits after LPS stimulation. Release of the p40 subunit was higher than release of the heterodimeric p70 molecule itself. Interestingly, the p40 subunit of IL12 can link together 


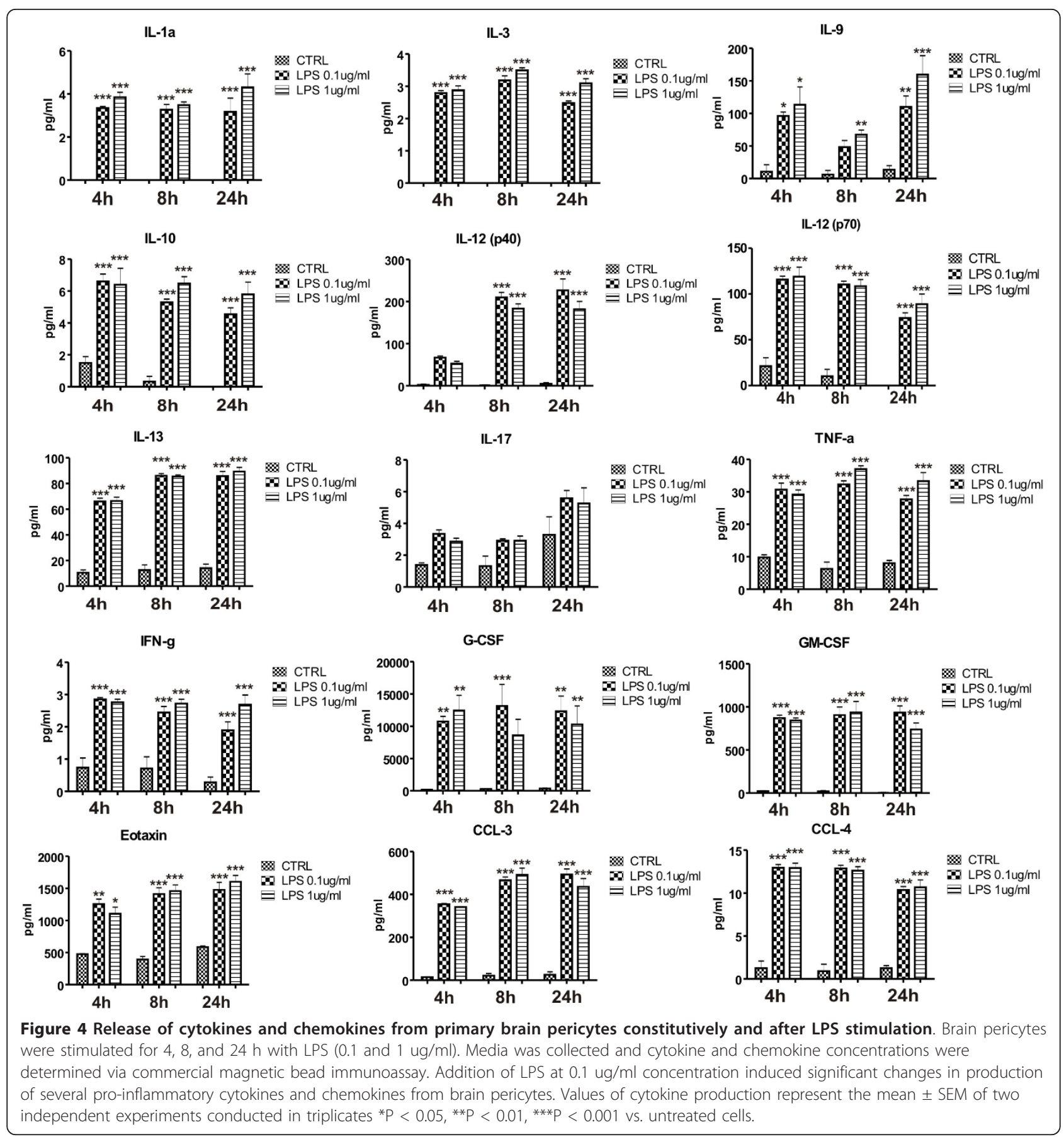

and this homodimeric form has been shown to increase expression of leukocyte chemoattractant factor (IL-16) in microglia [34].

IL-9 is another pleiotropic cytokine whose production was markedly increased after LPS stimulation of brain pericytes. IL-9 is mainly produced by T lymphocytes and mediates allergic inflammation in tissues such as the lung and intestine [35]. In the CNS, the IL-9 receptor complex is present on astrocytes and IL-9 stimulated astrocytes express CCL-20 chemokine which promotes infiltration of Th17 cells into the CNS [36].

IL-13 is known as an anti-inflammatory cytokine that is produced by microglia but not astrocytes or neurons after direct injection of LPS into the cortex. Neurons are required for IL-13 production by microglia and production of IL-13 by microglia leads to the death of activated microglia and enhancement of neuronal survival [37]. In our study, IL-13 production by brain pericytes 


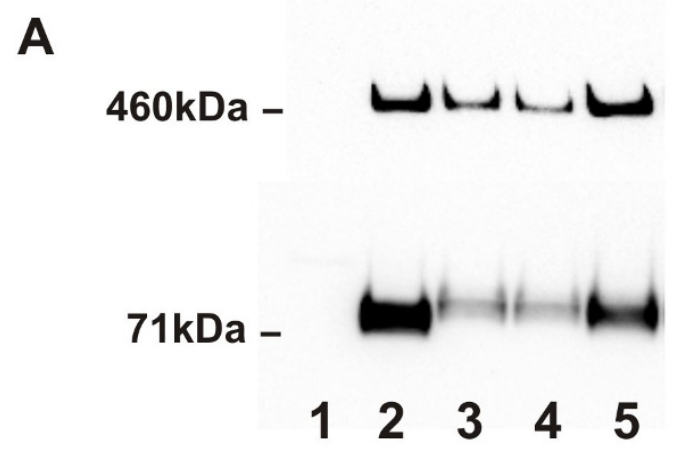

B
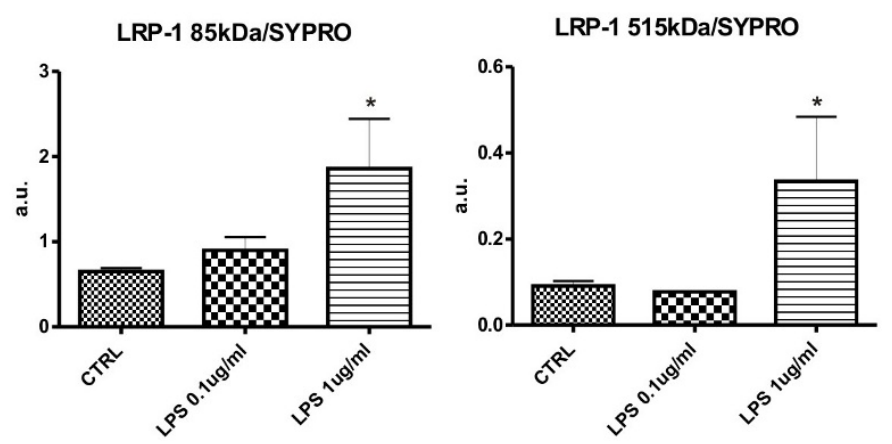

Figure 5 LPS induce up-regulation of LRP-1 expression in brain pericytes. Primary brain pericytes were stimulated for $24 \mathrm{~h}$ with LPS (0.1 and $1 \mathrm{ug} / \mathrm{ml}$ ). After $24 \mathrm{~h}$, expression of both LRP-1 subunits was analyzed by western blot as described in the Material and methods. LPS at 1 $\mathrm{ug} / \mathrm{ml}$ concentration induced significant increases in expression of the large $(515 \mathrm{kDa})$ and small $(85 \mathrm{kDa})$ subunits of LRP-1. A representative western blot (A) and density quantification (B) based on ratios between the antibody signal (LRP-1 85 or $515 \mathrm{kDa}$ ) and total protein loading per lane (SYPRO) is shown. Lane designation: 1-PEA13 (LRP-1 knockout as negative control), 2-MEF1 (LRP-1 wild type as positive control), 3-CTRL, 4LPS $0.1 \mathrm{ug} / \mathrm{ml}$, 5-LPS $1 \mathrm{ug} / \mathrm{ml}$. Values represent the mean \pm SEM of two independent experiments $* P<0.05$ vs. untreated cells, $n=5$.

was elevated after LPS treatment; this shows that pericytes are a source of IL-13 as well.

Additionally, compared to published results from LPS treated mouse microglia [38], production of IL1- $\alpha$ and TNF-alpha, a two typical proinflammatory cytokines, by brain pericytes was low. This shows that although pericytes and microglia both respond to LPS, the profile of cytokines released is different.

Recently an interesting study comparing the gene profile expression of different cell components of neurovascular unit in adult or during the development was published. The study revealed several important genes that are involved in pericyte-endothelial signaling such as transforming growth factor beta superfamily members bmp5 and nodal [39]. It would be interesting to perform such study with immune-challenged neurovascular unit as well.

Neurodegenerative processes are closely associated with neuroinflammation [40]. In Alzheimer's disease, increased production and impaired transport lead to accumulation of toxic amyloid beta peptide deposits along the vascular system in patients affected by this disease. LRP-1 at the brain endothelial cell is an important transporter for the brain-to-blood efflux of amyloid beta peptide [41] and in neurons is important in the processing of amyloid precursor protein $[42,43]$. It has been shown previously that human brain pericytes express LRP-1 and that the expression is increased after incubation of cells with amyloid beta peptide [44]. It is likely that pericyte LRP-1 contributes to the uptake and processing of amyloid beta peptide and amyloid precursor protein. Interestingly, accumulation of amyloid beta peptide within the pericyte bodies have been previously described for early onset familial $[45,46]$ and for sporadic Alzheimer's disease [47]. In line with these observations, we analyzed the expression of LRP-1 in brain pericytes during brain inflammation. We demonstrated that the expression of both subunits of LRP-1 is increased in brain pericytes under inflammatory conditions.

\section{Conclusions}

In conclusion, our results as presented here show that cultured mouse brain pericytes secreting NO, cytokines, and chemokines and responding to LPS stimulation. We also showed that pericytes in-vitro express LRP-1, an important regulator of the levels of amyloid beta peptide in the brain, and that expression is influenced by LPS. These immunoactive properties of cultured pericytes suggest mechanisms by which they can act as an integral part of the neurovascular unit during brain inflammatory processes such as brain infections and neurodegenerative processes.

\section{List of abbreviations}

BBB: blood-brain barrier; NO: nitric oxide; LRP-1: lipoprotein receptor-related protein-1; CD11B: cluster of differentiation molecule 11B; LPS: lipopolysaccharide; GFAP: glial fibrillary acidic protein; iNOS-2: inducible NO synthase-2; MAPK: mitogen-activated protein kinase.

Acknowledgements and funding

Supported by VA Merit Review, RO1 AG029839, and R01 DK083485.

\section{Author details}

'Geriatrics Research Education and Clinical Center, Veterans Affairs Puget Sound Health Care System, Seattle, Washington, USA. ${ }^{2}$ Division of Gerontology and Geriatric Medicine, Department of Internal Medicine, University of Washington, Seattle, Washington, USA. ${ }^{3}$ Department of Pharmacological and Physiological Sciences, Saint Louis University School of 
Medicine, St. Louis, MO USA. ${ }^{4}$ Institute of Neuroimmunology, Slovak Academy of Sciences, Bratislava, Slovakia.

\section{Authors' contributions}

AK designed the study, performed the bulk of the experiments and analyzed all data. AK and WB wrote the manuscript. ME performed the western blot analysis. All authors have read and approved the final version of this manuscript.

\section{Competing interests}

The authors declare that they have no competing interests.

Received: 17 August 2011 Accepted: 13 October 2011

Published: 13 October 2011

\section{References}

1. Neuwelt E, Abbott NJ, Abrey L, Banks WA, Blakley B, Davis T, Engelhardt B, Grammas P, Nedergaard M, Nutt J, et al: Strategies to advance translational research into brain barriers. Lancet Neurol 2008, 7:84-96.

2. Bonkowski D, Katyshev V, Balabanov RD, Borisov A, Dore-Duffy P: The CNS microvascular pericyte: pericyte-astrocyte crosstalk in the regulation of tissue survival. Fluids Barriers CNS 2011, 8:8

3. Mae M, Armulik A, Betsholt C: Getting to Know the Cast-Cellular Interactions and Signaling at the Neurovascular Unit. Curr Pharm Des 2011, 9:9.

4. Daneman $R$, Zhou L, Kebede AA, Barres BA: Pericytes are required for blood-brain barrier integrity during embryogenesis. Nature 2010, 468:562-566.

5. Bell RD, Winkler EA, Sagare AP, Singh I, LaRue B, Deane R, Zlokovic BV: Pericytes control key neurovascular functions and neuronal phenotype in the adult brain and during brain aging. Neuron 2010, 68:409-427.

6. Armulik A, Genove G, Mae M, Nisancioglu MH, Wallgard E, Niaudet C, He L, Norlin J, Lindblom P, Strittmatter K, et al: Pericytes regulate the bloodbrain barrier. Nature 2010, 468:557-561.

7. Ho KL: Ultrastructure of cerebellar capillary hemangioblastoma. IV. Pericytes and their relationship to endothelial cells. Acta Neuropathol 1985, 67:254-264.

8. Le BeuX YJ, Willemot J: Actin- and myosin-like filaments in rat brain pericytes. Anat Rec 1978, 190:811-826.

9. Bandopadhyay R, Orte C, Lawrenson JG, Reid AR, De Silva S, Allt G: Contractile proteins in pericytes at the blood-brain and blood-retinal barriers. J Neurocytol 2001, 30:35-44.

10. Dalkara T, Gursoy-Ozdemir Y, Yemisci M: Brain microvascular pericytes in health and disease. Acta Neuropathol 2011, 122:1-9.

11. Peppiatt CM, Howarth C, Mobbs P, Attwell D: Bidirectional control of CNS capillary diameter by pericytes. Nature 2006, 443:700-704.

12. Hamilton NB, Attwell D, Hall CN: Pericyte-mediated regulation of capillary diameter: a component of neurovascular coupling in health and disease. Front Neuroenergetics 2010, 2:5.

13. Dore-Duffy P, Katychev A, Wang X, Van Buren E: CNS microvascular pericytes exhibit multipotential stem cell activity. J Cereb Blood Flow Metab 2006, 26:613-624.

14. Balabanov R, Washington R, Wagnerova J, Dore-Duffy P: CNS microvascular pericytes express macrophage-like function, cell surface integrin alpha M, and macrophage marker ED-2. Microvasc Res 1996, 52:127-142.

15. Nishioku T, Dohgu S, Takata F, Eto T, Ishikawa N, Kodama KB, Nakagawa S, Yamauchi A, Kataoka Y: Detachment of brain pericytes from the basal lamina is involved in disruption of the blood-brain barrier caused by lipopolysaccharide-induced sepsis in mice. Cell Mol Neurobiol 2009, 29:309-316.

16. Nakagawa S, Deli MA, Kawaguchi H, Shimizudani T, Shimono T, Kittel A, Tanaka K, Niwa M: A new blood-brain barrier model using primary rat brain endothelial cells, pericytes and astrocytes. Neurochem Int 2009, 54:253-263.

17. Hagiwara M, Kobayashi K, Tadokoro T, Yamamoto Y: Application of SYPRO Ruby- and Flamingo-stained polyacrylamide gels to Western blot analysis. Anal Biochem 2010, 397:262-264.

18. Guillemin GJ, Brew BJ: Microglia, macrophages, perivascular macrophages, and pericytes: a review of function and identification. J Leukoc Biol 2004, 75:388-397.
19. Alliot F, Rutin J, Leenen PJ, Pessac B: Pericytes and periendothelial cells of brain parenchyma vessels co-express aminopeptidase $\mathrm{N}$, aminopeptidase A, and nestin. J Neurosci Res 1999, 58:367-378.

20. Cai J, Kehoe O, Smith GM, Hykin P, Boulton ME: The angiopoietin/Tie-2 system regulates pericyte survival and recruitment in diabetic retinopathy. Invest Ophthalmol Vis Sci 2008, 49:2163-2171.

21. Ramsauer M, Krause D, Dermietzel R: Angiogenesis of the blood-brain barrier in vitro and the function of cerebral pericytes. Faseb J 2002, 16:1274-1276.

22. Armulik A, Genove G, Betsholtz C: Pericytes: developmental, physiological, and pathological perspectives, problems, and promises. Dev Cell 2011 21:193-215.

23. Krueger M, Bechmann I: CNS pericytes: concepts, misconceptions, and a way out. Glia 2010, 58:1-10.

24. Saura J: Microglial cells in astroglial cultures: a cautionary note. $J$ Neuroinflammation 2007, 4:26.

25. Murphy S: Production of nitric oxide by glial cells: regulation and potential roles in the CNS. Glia 2000, 29:1-13.

26. Foster MW: Methodologies for the characterization, identification and quantification of S-nitrosylated proteins. Biochim Biophys Acta 2011, 4:4.

27. Foster MW, Hess DT, Stamler JS: Protein S-nitrosylation in health and disease: a current perspective. Trends Mol Med 2009, 15:391-404.

28. Koistinaho M, Koistinaho J: Role of p38 and p44/42 mitogen-activated protein kinases in microglia. Glia 2002, 40:175-183.

29. Kim CO, Huh AJ, Kim MS, Chin BS, Han SH, Choi SH, Jeong SJ, Choi HK, Choi JY, Song YG, Kim JM: LPS-induced vascular endothelial growth factor expression in rat lung pericytes. Shock 2008, 30:92-97.

30. Constantinescu CS, Goodman DB, Hilliard B, Wysocka M, Cohen JA: Murine macrophages stimulated with central and peripheral nervous system myelin or purified myelin proteins release inflammatory products. Neurosci Lett 2000, 287:171-174.

31. Swardfager W, Lanctot K, Rothenburg L, Wong A, Cappell J, Herrmann N: A meta-analysis of cytokines in Alzheimer's disease. Biol Psychiatry 2010, 68:930-941.

32. Zipris D, Greiner DL, Malkani S, Whalen B, Mordes JP, Rossini AA: Cytokine gene expression in islets and thyroids of BB rats. IFN-gamma and IL$12 p 40$ mRNA increase with age in both diabetic and insulin-treated nondiabetic BB rats. J Immunol 1996, 156:1315-1321.

33. Jana M, Dasgupta S, Pal U, Pahan K: IL-12 p40 homodimer, the so-called biologically inactive molecule, induces nitric oxide synthase in microglia via IL-12R beta 1. Glia 2009, 57:1553-1565.

34. Jana M, Pahan K: IL-12 p40 homodimer, but not IL-12 p70, induces the expression of IL-16 in microglia and macrophages. Mol Immunol 2009, 46:773-783.

35. Goswami R, Kaplan MH: A brief history of IL-9. J Immunol 2011 186:3283-3288

36. Zhou $Y$, Sonobe $Y$, Akahori $T$, Jin $S$, Kawanokuchi J, Noda M, Iwakura $Y$, Mizuno T, Suzumura A: IL-9 promotes Th17 cell migration into the central nervous system via CC chemokine ligand-20 produced by astrocytes. J Immunol 2011, 186:4415-4421.

37. Shin WH, Lee DY, Park KW, Kim SU, Yang MS, Joe EH, Jin BK: Microglia expressing interleukin-13 undergo cell death and contribute to neuronal survival in vivo. Glia 2004, 46:142-152.

38. Lu X, Ma L, Ruan L, Kong Y, Mou H, Zhang Z, Wang Z, Wang JM, Le Y: Resveratrol differentially modulates inflammatory responses of microglia and astrocytes. J Neuroinflammation 2010, 7:46.

39. Daneman R, Zhou L, Agalliu D, Cahoy JD, Kaushal A, Barres BA: The mouse blood-brain barrier transcriptome: a new resource for understanding the development and function of brain endothelial cells. PLoS One 2010, 5: e13741

40. Eikelenboom P, Bate C, Van Gool WA, Hoozemans JJ, Rozemuller JM, Veerhuis R, Williams A: Neuroinflammation in Alzheimer's disease and prion disease. Glia 2002, 40:232-239.

41. Zlokovic BV: Clearing amyloid through the blood-brain barrier. Neurochem 2004, 89:807-811.

42. Bu G, Maksymovitch EA, Nerbonne JM, Schwartz AL: Expression and function of the low density lipoprotein receptor-related protein (LRP) in mammalian central neurons. J Biol Chem 1994, 269:18521-18528.

43. Lillis AP, Van Duyn LB, Murphy-Ullrich JE, Strickland DK: LDL receptorrelated protein 1: Unique tissue-specific functions revealed by selective gene knockout studies. Physiological Reviews 2008, 88:887-918. 
44. Wilhelmus MM, Otte-Holler I, van Triel JJ, Veerhuis R, Maat-Schieman ML, Bu G, de Waal RM, Verbeek MM: Lipoprotein receptor-related protein-1 mediates amyloid-beta-mediated cell death of cerebrovascular cells. Am J Pathol 2007, 171:1989-1999.

45. Wegiel J, Wisniewski HM: Tubuloreticular structures in microglial cells, pericytes and endothelial cells in Alzheimer's disease. Acta Neuropathol 1992, 83:653-658.

46. Wisniewski HM, Wegiel J, Wang KC, Lach B: Ultrastructural studies of the cells forming amyloid in the cortical vessel wall in Alzheimer's disease. Acta Neuropathol 1992, 84:117-127.

47. Szpak GM, Lewandowska E, Wierzba-Bobrowicz T, Bertrand E, Pasennik E, Mendel T, Stepien T, Leszczynska A, Rafalowska J: Small cerebral vessel disease in familial amyloid and non-amyloid angiopathies: FAD-PS-1 (P117L) mutation and CADASIL. Immunohistochemical and ultrastructural studies. Folia Neuropathol 2007, 45:192-204.

doi:10.1186/1742-2094-8-139

Cite this article as: Kovac et al: Brain microvascular pericytes are immunoactive in culture: cytokine, chemokine, nitric oxide, and LRP-1 expression in response to lipopolysaccharide. Journal of Neuroinflammation 2011 8:139.

\section{Submit your next manuscript to BioMed Central and take full advantage of:}

- Convenient online submission

- Thorough peer review

- No space constraints or color figure charges

- Immediate publication on acceptance

- Inclusion in PubMed, CAS, Scopus and Google Scholar

- Research which is freely available for redistribution

Submit your manuscript at www.biomedcentral.com/submit 